\title{
Composition control of manganite perovskites in metalorganic chemical vapor deposition with in situ spectroscopic monitoring
}

\section{$\operatorname{AUTHOR}(\mathrm{S})$ :}

Nakamura, T; Tai, R; Nishimura, T; Tachibana, K

\section{CITATION:}

Nakamura, T ...[et al]. Composition control of manganite perovskites in metalorganic chemical vapor deposition with in situ spectroscopic monitoring. JOURNAL OF APPLIED PHYSICS 2005, 97(10): 10H712.

\section{ISSUE DATE:}

2005-05-15

URL:

http://hdl.handle.net/2433/50173

\section{RIGHT:}

Copyright 2005 American Institute of Physics. This article may be downloaded for personal use only. Any other use requires prior permission of the author and the American Institute of Physics. 


\title{
Composition control of manganite perovskites in metalorganic chemical vapor deposition with in situ spectroscopic monitoring
}

\author{
Toshihiro Nakamura, ${ }^{a}$ Ryusuke Tai, Takuro Nishimura, and Kunihide Tachibana \\ Department of Electronic Science and Engineering, Kyoto University, Kyotodaigaku-Katsura, Nishikyo-ku, \\ Kyoto 615-8510, Japan
}

(Presented on 8 November 2004; published online 11 May 2005)

\begin{abstract}
Using in situ infrared absorption spectroscopy, the behavior of the film precursors, tris(dipivaloylmethanato)lanthanum $\quad\left[\mathrm{La}(\mathrm{DPM})_{3}\right], \quad$ tris(dipivaloylmethanato)manganese $\left[\mathrm{Mn}(\mathrm{DPM})_{3}\right]$, and bis(dipivaloylmethanato)strontium $\left[\mathrm{Sr}(\mathrm{DPM})_{2}\right]$, in the gas phase was investigated under actual chemical vapor deposition conditions of manganite perovskites. The temperature dependence of the infrared absorption indicates that $\mathrm{La}(\mathrm{DPM})_{3}, \mathrm{Mn}(\mathrm{DPM})_{3}$, and $\operatorname{Sr}(\mathrm{DPM})_{2}$ differ significantly in the decomposition temperature. The atomic composition of the deposited film can be controlled on the basis of the precursor densities obtained by the in situ spectroscopic measurements. The composition control based on the in situ monitoring technique is expected to improve the reproducibility of the magnetic property of the deposited film. (C) 2005 American Institute of physics. [DOI: 10.1063/1.1853895]
\end{abstract}

\section{INTRODUCTION}

Recently, half-metallic materials have been receiving much attention due to the keen technological interest in their application to electronic devices utilizing spin degree of freedom of conducting charge carriers. Compared to tunneling junctions based on the conventional ferromagnetic metal electrodes, magnetoresistance in the tunneling junctions made of manganite perovskites, such as ( $\mathrm{La}, \mathrm{Sr}) \mathrm{MnO}_{3}$ (LSMO), is expected to be larger. The physical property of LSMO is closely connected with its atomic composition. As for the film deposition method of LSMO, metal-organic chemical-vapor deposition (MOCVD) is particularly suited for the device applications due to the ease in changing the atomic composition, its applicability to the large area deposition, and its excellent step coverage. The good reproducibility of the magnetic property of the deposited film is strictly required for the practical use of MOCVD. Although intensive works have been performed for the film characterization, ${ }^{1-8}$ the deposition chemistry is still not well understood. Recently, we investigated gas phase reactions in MOCVD of $(\mathrm{Ba}, \mathrm{Sr}) \mathrm{TiO}_{3}$ films by in situ infrared absorption spectroscopy ${ }^{9-14}$ and microdischarge optical emission spectroscopy. ${ }^{15,16}$ In this work, in situ spectroscopic monitoring was carried out to improve the reproducibility of the atomic composition of LSMO films.

\section{EXPERIMENT}

Figure 1 shows a schematic diagram of the liquid-source MOCVD apparatus. The experimental setup for the liquidsource CVD was the same as that described previously. ${ }^{9-17}$ We used tris(dipivaloylmethanato)lanthanum $\left[\mathrm{La}(\mathrm{DPM})_{3}\right]$, tris(dipivaloylmethanato)manganese $\left[\mathrm{Mn}(\mathrm{DPM})_{3}\right]$, and bis(dipivaloylmethanato)strontium $\left[\mathrm{Sr}(\mathrm{DPM})_{2}\right]$ as the source materials. These source materials were dissolved in tetrahy-

\footnotetext{
${ }^{a)}$ Electronic mail: tosihiro@kuee.kyoto-u.ac.jp
}

drofuran (THF, $\mathrm{C}_{4} \mathrm{H}_{8} \mathrm{O}$ ) at a concentration of $0.1 \mathrm{~mol} / \mathrm{l}$. After each dissolved source was introduced into a vaporizer by $\mathrm{N}_{2}$ carrier gas at $200 \mathrm{sccm}$, the vaporized source was transported into the MOCVD reactor and subsequently mixed with $\mathrm{O}_{2}$ oxidant gas. The pressure in the reactor was maintained at 10 Torr. Thin films were deposited on 6 in. diameter $\mathrm{Si}(100)$ substrates. The atomic composition of the deposited film was evaluated by $\mathrm{x}$-ray photoelectron spectroscopy (XPS) after etching of the film surface. We observed IR absorption spectra under actual CVD conditions. Details of the in situ infrared absorption measurements have been described elsewhere. ${ }^{9-14}$

\section{RESULTS AND DISCUSSION}

We carried out in situ measurements of the infrared absorption spectra of $\mathrm{La}(\mathrm{DPM})_{3}, \mathrm{Mn}(\mathrm{DPM})_{3}$, and $\mathrm{Sr}(\mathrm{DPM})_{2}$.

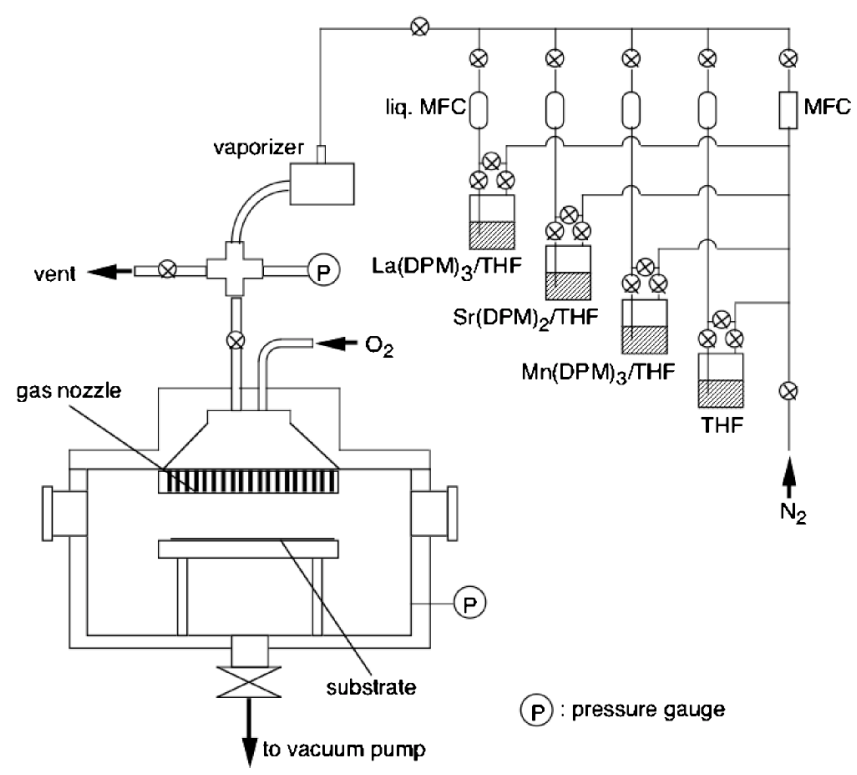

FIG. 1. Schematic diagram of the liquid-source CVD apparatus. 

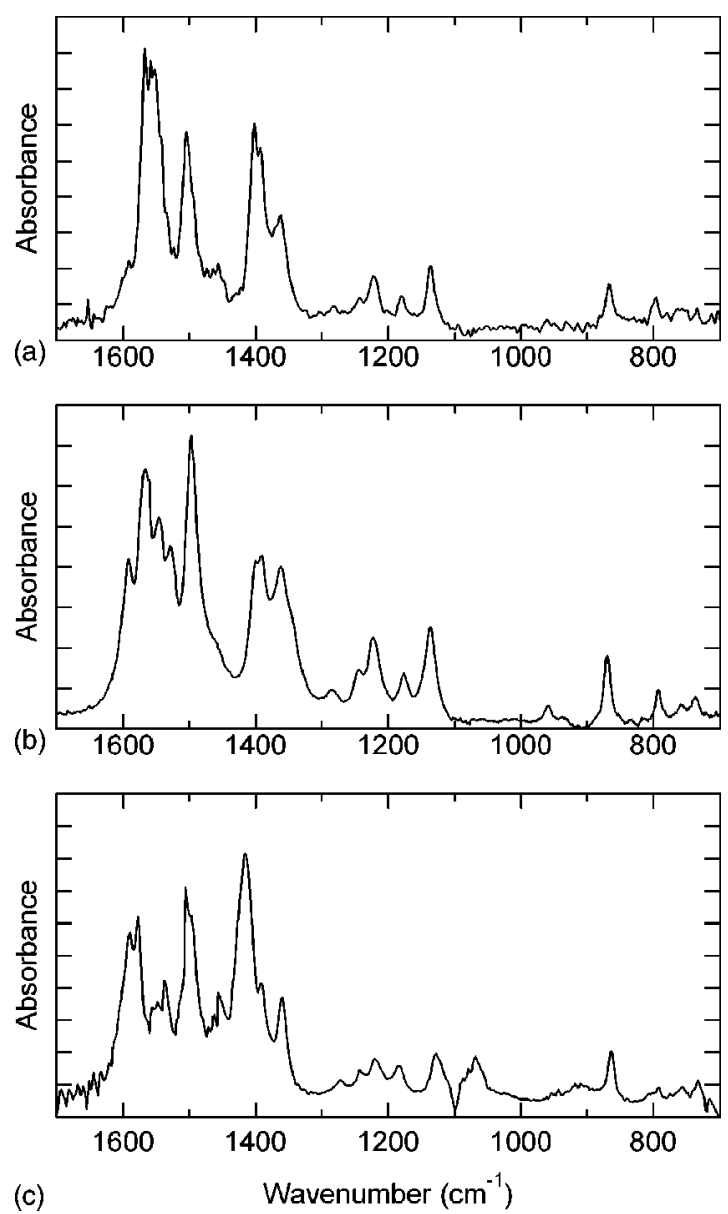

FIG. 2. In situ infrared absorption spectra of (a) $\mathrm{La}(\mathrm{DPM})_{3}$, (b) $\mathrm{Mn}(\mathrm{DPM})_{3}$, and (c) $\operatorname{Sr}(\mathrm{DPM})_{2}$.

The observed infrared spectra in the absorbance mode at the substrate temperature of $240{ }^{\circ} \mathrm{C}$ were shown in Fig. 2. These spectra were obtained by subtracting the THF absorption from the observed spectra. Infrared spectral assignments were carried out on the basis of the density functional theory calculations. ${ }^{18}$ The infrared absorption in the regions of $1700-700 \mathrm{~cm}^{-1}$ is considered to be due to the DPM ligands.

Based on the temperature dependence of the infrared absorption spectra, we compared the decomposition mechanisms of $\mathrm{La}(\mathrm{DPM})_{3}, \mathrm{Mn}(\mathrm{DPM})_{3}$, and $\operatorname{Sr}(\mathrm{DPM})_{2}$. Figure 3 shows the temperature dependence of the infrared absorption at the substrate temperature between $240{ }^{\circ} \mathrm{C}$ and $640{ }^{\circ} \mathrm{C}$. The vibrational spectral peak of $\mathrm{La}(\mathrm{DPM})_{3}, \mathrm{Mn}(\mathrm{DPM})_{3}$, and $\mathrm{Sr}(\mathrm{DPM})_{2}$ at $865 \mathrm{~cm}^{-1}$ is assigned to $\mathrm{C}-\mathrm{C}\left(\mathrm{CH}_{3}\right)_{3}$ stretching mode with the in-plane DPM ring deformation. As the substrate temperature increased, the absorbance derived from these source molecules decreased. This decrease is due to the thermal decomposition of the source molecule. The absorbance of $\mathrm{Mn}(\mathrm{DPM})_{3}$ decreases rapidly in comparison with that of $\mathrm{La}(\mathrm{DPM})_{3}$, while the absorbance of $\mathrm{Mn}(\mathrm{DPM})_{3}$ decreases at a higher temperature than that of $\operatorname{Sr}(\mathrm{DPM})_{2}$. The temperature dependence of the absorption indicates that $\mathrm{La}(\mathrm{DPM})_{3}, \mathrm{Mn}(\mathrm{DPM})_{3}$, and $\mathrm{Sr}(\mathrm{DPM})_{2}$ differ significantly in the decomposition temperature. Therefore, the $\mathrm{La}, \mathrm{Sr}$, and Mn contents in the deposited film may be different from those of the liquid source, depending on the deposition tem-

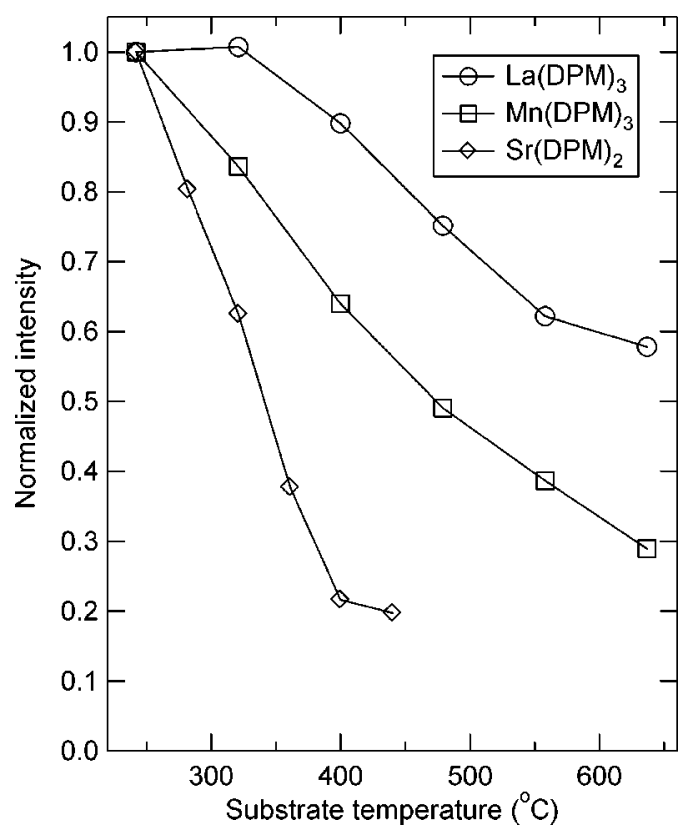

FIG. 3. Temperature dependence of the infrared absorptions of $\mathrm{La}(\mathrm{DPM})_{3}$, $\mathrm{Mn}(\mathrm{DPM})_{3}$, and $\operatorname{Sr}(\mathrm{DPM})_{2}$ at $865 \mathrm{~cm}^{-1}$.

perature. It is desirable that the flow rate of each CVD source is controlled on the basis of the relative precursor densities obtained by the in situ spectroscopic measurements.

We deposited lanthanum manganite films by changing the source mixing ratio of $\mathrm{La}(\mathrm{DPM})_{3} /\left[\mathrm{La}(\mathrm{DPM})_{3}\right.$ $\left.+\mathrm{Mn}(\mathrm{DPM})_{3}\right]$. Figure 4 shows the atomic composition of the lanthanum manganite films deposited at the substrate temperature of $560{ }^{\circ} \mathrm{C}$. When the $\mathrm{La}(\mathrm{DPM})_{3} /\left[\mathrm{La}(\mathrm{DPM})_{3}\right.$ $\left.+\mathrm{Mn}(\mathrm{DPM})_{3}\right]$ ratio was below $50 \%$, no incorporation of carbon was detected by XPS measurements. The atomic composition ratio of $\mathrm{La}: \mathrm{Mn}=1: 1$ was obtained by setting the $\mathrm{La}(\mathrm{DPM})_{3} /\left[\mathrm{La}(\mathrm{DPM})_{3}+\mathrm{Mn}(\mathrm{DPM})_{3}\right]$ ratio to be about $33 \%$. The obtained film with the atomic composition ratio of La:Mn=1:1 was confirmed to be polycrystalline by $\mathrm{x}$-ray diffractometry.

Figure 5 shows the atomic composition of the strontiumdoped lanthanum manganite films deposited at the substrate

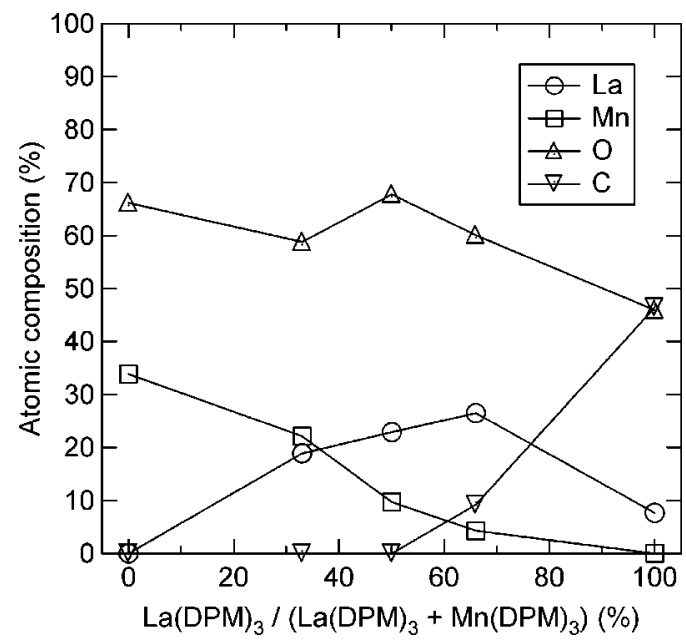

FIG. 4. Atomic composition in lanthanum manganite films as a function of the flow rate ratio of $\mathrm{La}(\mathrm{DPM})_{3}$ and $\mathrm{Mn}(\mathrm{DPM})_{3}$. 


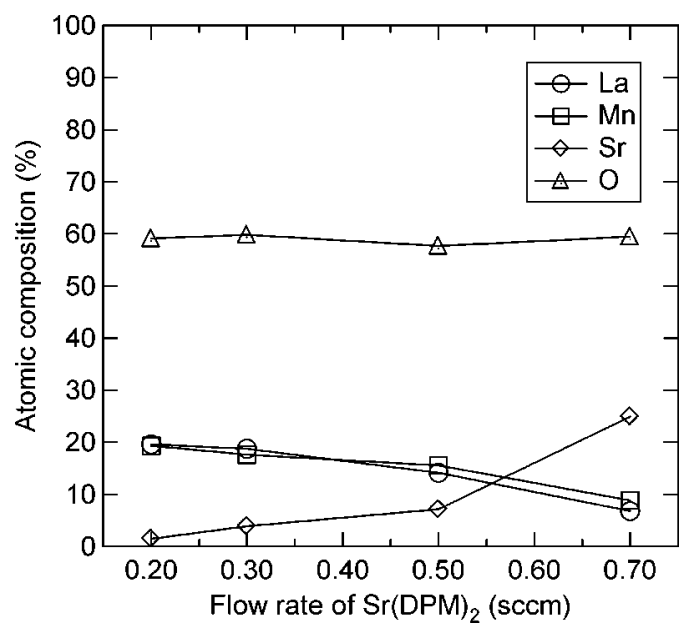

FIG. 5. Atomic composition in strontium-doped lanthanum manganite films as a function of the flow rate of $\operatorname{Sr}(\mathrm{DPM})_{2}$. The flow rates of $\mathrm{La}(\mathrm{DPM})_{3}$ and $\mathrm{Mn}(\mathrm{DPM})_{3}$ were fixed at constant values of $0.1 \mathrm{sccm}$ and $0.2 \mathrm{sccm}$, respectively.

temperature of $480{ }^{\circ} \mathrm{C}$. The flow rate of $\operatorname{Sr}(\mathrm{DPM})_{2} / \mathrm{THF}$ solution was changed from 0.2 to $0.7 \mathrm{sccm}$, while the flow rates of the $\mathrm{La}(\mathrm{DPM})_{3} / \mathrm{THF}$ and $\mathrm{Mn}(\mathrm{DPM})_{3} / \mathrm{THF}$ solutions were fixed at constant values of 0.1 and $0.2 \mathrm{sccm}$, respectively. The lanthanum manganite film with the appropriate amount of the doped strontium can be deposited without any incorporation of carbon.

\section{ACKNOWLEDGMENTS}

The authors would like to thank Kyoto University Venture Business Laboratory (KU-VBL) for the support. This work was partly supported by Grant-in-Aid for Young Sci- entists (Grant No. 16760617) from the Ministry of Education, Culture, Sports, Science and Technology of Japan, and also by Kyoto Nanotechnology Cluster.

${ }^{1}$ G. J. Snyder, R. Hiskes, S. Dicarolis, M. R. Berasley, and T. H. Geballe, Phys. Rev. B 53, 14434 (1996).

${ }^{2}$ J. J. Heremans, M. Carris, S. Watts, X. Yu, K. H. Dahmen, and S. von Molnar, J. Appl. Phys. 81, 4967 (1997).

${ }^{3}$ D. Studebaker, M. Todd, C. Seegel, and T. H. Baum, Mater. Sci. Eng., B 56, 168 (1998).

${ }^{4}$ S. M. Watts, M. Li, S. Wirth, K.-H. Dahmen, S. von Molnar, P. Xiong, A. S. Katz, and R. C. Dynes, J. Appl. Phys. 85, 4791 (1999).

${ }^{5}$ C. Dubourdieu, M. Audier, J. P. Senateur, and J. Pierre, J. Appl. Phys. 86, 6945 (1999).

${ }^{6}$ K. Steenbeck, T. Habisreuther, C. Dubourdieu, and J. P. Senateur, Appl. Phys. Lett. 80, 3361 (2002).

${ }^{7}$ A. Abrutis, V. Plausinaitiene, V. Kubilius, A. Teiserskis, Z. Saltyte, R. Butkute, and J. P. Senateur, Thin Solid Films 413, 32 (2002).

${ }^{8}$ C. Dubourdieu, M. Audier, H. Roussel, J. P. Senateur, and J. Pierre, J. Appl. Phys. 92, 379 (2002).

${ }^{9}$ T. Nakamura, S. Momose, R. Sahara, and K. Tachibana, Jpn. J. Appl. Phys., Part 1 41, 6624 (2002).

${ }^{10}$ S. Momose, R. Sahara, T. Nakamura, and K. Tachibana, Jpn. J. Appl. Phys., Part 1 40, 5501 (2001).

${ }^{11}$ S. Momose, T. Nakamura, and K. Tachibana, Jpn. J. Appl. Phys., Part 1 39, 5384 (2000).

${ }^{12}$ T. Nakamura, T. Nishimura, S. Momose, and K. Tachibana, J. Electrochem. Soc. 151, C605 (2004).

${ }^{13}$ T. Nakamura, T. Nishimura, and K. Tachibana, J. Electrochem. Soc. 151, C806 (2004).

${ }^{14}$ T. Nakamura, T. Nishimura, R. Tai, and K. Tachibana, Mater. Sci. Eng., B (to be published).

${ }^{15}$ S. Momose, T. Nakamura, and K. Tachibana, Jpn. J. Appl. Phys., Part 1 41, 778 (2002).

${ }^{16}$ S. Momose, T. Nakamura, and K. Tachibana, Jpn. J. Appl. Phys., Part 1 39, 555 (2000).

${ }^{17}$ T. Nakamura, S. Momose, and K. Tachibana, Jpn. J. Appl. Phys., Part 1 40, 6619 (2001).

${ }^{18}$ T. Nakamura and K. Tachibana, Jpn. J. Appl. Phys., Part 1 40, 338 (2001). 